\title{
Association of thigh and paraspinal muscle composition in young adults using chemical shift encoding-based water-fat MRI
}

\author{
Egon Burian $^{1 \#}$, Stephanie Inhuber ${ }^{2 \#}$, Sarah Schlaeger ${ }^{1,3}$, Michael Dieckmeyer ${ }^{1}$, Elisabeth Klupp ${ }^{1}$, \\ Daniela Franz ${ }^{3}$, Dominik Weidlich ${ }^{3}$, Nico Sollmann ${ }^{1}$, Maximilian Löffler ${ }^{1}$, Ansgar Schwirtz ${ }^{2}$, \\ Ernst J. Rummeny ${ }^{3}$, Claus Zimmer ${ }^{1}$, Jan S. Kirschke ${ }^{1}$, Dimitrios C. Karampinos ${ }^{3}$, Thomas Baum ${ }^{1}$ \\ ${ }^{1}$ Department of Diagnostic and Interventional Neuroradiology, Klinikum rechts der Isar, ${ }^{2}$ Department of Sport and Health Sciences, ${ }^{3}$ Department of \\ Diagnostic and Interventional Radiology, Klinikum rechts der Isar, Technical University of Munich, Munich, Germany
}

\#These authors contributed equally to this work.

Correspondence to: Egon Burian, MD, DMD. Department of Diagnostic and Interventional Neuroradiology, Klinikum rechts der Isar, Technical University of Munich, Ismaninger Str. 22, 81675 Munich, Germany. Email: egon.burian@tum.de.

Background: Paraspinal and thigh muscles comprise the major muscle groups of the body. We investigated the composition of the psoas, erector spinae, quadriceps femoris and hamstring muscle groups and their association to each other using chemical shift encoding-based water-fat magnetic resonance imaging (MRI) in adult volunteers. Our aim was to elucidate fat distribution patterns within these muscle groups.

Methods: Thirty volunteers [15 males, age: $30.5 \pm 4.9$ years, body mass index (BMI): $27.6 \pm 2.8 \mathrm{~kg} / \mathrm{m}^{2}$ and 15 females, age: $29.9 \pm 7.0$ years, BMI: $25.8 \pm 1.4 \mathrm{~kg} / \mathrm{m}^{2}$ ] were recruited for this study. A six-echo $3 \mathrm{D}$ spoiled gradient echo sequence was used for chemical shift encoding-based water-fat separation at the lumbar spine and bilateral thigh. Proton density fat fraction (PDFF), cross-sectional area (CSA) and contractile mass index (CMI) of the psoas, erector spinae, quadriceps femoris and hamstring muscle groups were determined bilaterally and averaged over both sides.

Results: CSA and CMI values calculated for the erector spinae, psoas, quadriceps and hamstring muscle groups showed significant differences between men and women $(\mathrm{P}<0.05)$. With regard to PDFF measurement only the erector spinae showed significant differences between men and women $(9.5 \% \pm 2.4 \%$ vs. $11.7 \% \pm 2.8 \%, \mathrm{P}=0.015)$. The $\mathrm{CMI}$ of the psoas muscle as well as the erector spinae muscle showed significant correlations with the quadriceps muscle $(\mathrm{r}=0.691, \mathrm{P}<0.0001$ and $\mathrm{r}=0.761, \mathrm{P}<0.0001)$ and the hamstring group $(\mathrm{r}=0.588, \mathrm{P}=0.001$ and $\mathrm{r}=0.603, \mathrm{P}<0.0001)$.

Conclusions: CMI values of the erector spinae and psoas muscles were associated with those of the quadriceps femoris and hamstring musculature. These findings suggest a concordant spatial fat accumulation within the analyzed muscles in young adults and warrants further investigations in ageing and diseased muscle.

Keywords: Magnetic resonance imaging (MRI); quantitative imaging; proton density fat fraction (PDFF); muscle composition; paraspinal muscle; thigh muscle

Submitted Jul 10, 2019. Accepted for publication Nov 07, 2019.

doi: 10.21037/qims.2019.11.08

View this article at: http://dx.doi.org/10.21037/qims.2019.11.08 


\section{Introduction}

Sarcopenia is considered as a progressive and generalized musculoskeletal disorder associated with impaired muscle quality and muscular performance increasing the risk of fracture, disability and mortality according to a recent consensus paper on modified taxonomic recommendations (1-3). Analogously to the described entity, cachexia is a severe, adverse side effect of advanced oncological diseases accompanied by elevated general catabolic activity, muscle wasting and overall therapeutic outcome (4-6). To detect the onset of cachexia in a clinical setting and reduce or delay the aggravating and life quality limiting side effects, the merit of several diagnostic modalities was evaluated in previous studies $(7,8)$. The described catabolic alterations in these disease entities require precise diagnostic assessment of pathophysiological changes in muscle composition and morphology for subsequent implementation in clinical diagnostics (9).

There are established imaging methods to assess muscle mass and composition including dual energy $\mathrm{X}$-ray absorptiometry (DXA) and computed tomography (CT) (10). Single-voxel proton magnetic resonance spectroscopy (MRS) and chemical shift encoding-based water-fat magnetic resonance imaging (MRI) are gaining importance in preclinical and clinical settings. They enable the investigator to extract surrogate parameters of the muscle composition like the proton density fat fraction (PDFF) and even for the identification of the chemical structure of fatty acids and their magnitude with high congruence to histology (11). In previous studies, Azzabou et al. and Barnouin et al. already described water-fat separation imaging based on a 3-point Dixon technique to reliably quantify intramuscular fat compositions in the quadriceps femoris using manual segmentation methods $(12,13)$.

In the past a vast amount of literature has been published on water-fat MRI studying the muscle composition of major muscle groups like the paraspinal or thigh musculature in healthy adults (12-18). These studies showed that the thigh and the paraspinal musculature morphology, i.e., their muscular fatty infiltration and their cross-sectional area (CSA) is individually susceptible to age and additionally but also varying with different anatomic locations $(12,14,16)$.

In a clinical setting the normative studies conducted investigating fat distribution patterns in healthy collectives can provide physiological benchmark values with regard to improve early diagnostics catabolic diseases like sarcopenia or cachexia. However, as one major confounding factor limiting the benefit of quantitative MRI in displaying muscular fatty infiltration in a clinical setting age has to be kept in mind. Against this background Dahlqvist et al. and Crawford et al. amongst others already showed the strong association of senescent, healthy adults and muscle loss $(15,16)$.

It would be of interest to elucidate the association of large muscle groups' composition, e.g., the thigh and paraspinal musculature, as they comprise the major muscle compartments of the body and are of relevance in musculoskeletal disorders. A homo- or heterogenous muscle composition across different muscle groups affects the choice where to measure the muscle composition and disease status best. Furthermore, it will give us more insights into the muscle (patho-)physiology.

Therefore, this study investigated the fat distribution patterns of the psoas, erector spinae, quadriceps femoris and hamstring muscle groups and their association to each other using chemical shift encoding-based water-fat MRI in adult volunteers.

\section{Methods}

\section{Subjects}

Thirty Caucasian volunteers with self-reported clean medical history (male $=15$, female $=15$ ) were recruited for this study. A body mass index (BMI) between 20 and $33 \mathrm{~kg} / \mathrm{m}^{2}$ and an age between 20 and 40 years were defined as inclusion criteria to obtain rather broad BMI and age ranges. All subjects were right-footed. Exclusion criteria were history of metabolic disorders, spine or thigh trauma, and MRI contraindications.

\section{MRI}

Subjects underwent MRI at 3 Tesla (Ingenia, Philips Healthcare, Best, Netherlands) in supine position using anterior and posterior coil arrays.

The conducted imaging protocol comprised an axiallyprescribed, six-echo three-dimensional spoiled gradient echo sequence in three stacks for chemical shift encodingbased water-fat separation at the lumbar spine and thigh. The sequence is a standard product and available on Philips scanners (Philips Healthcare, Best, Netherlands). The dedicated sequence parameters were set as follows: repetition time (TR)/echo time (TE) $\mathrm{min} / \Delta \mathrm{TE}=6.4 / 1.1 / 0.8 \mathrm{~ms}$, field of view $(\mathrm{FOV})=220 \times 401 \times 252 \mathrm{~mm}^{3}$, acquisition matrix $=68 \times 150$, voxel size $=3.2 \times 2.0 \times 4.0 \mathrm{~mm}^{3}$, frequency encoding direction $=\mathrm{L} / \mathrm{R}$, no SENSE, scan time $=1 \mathrm{~min}$ and $25 \mathrm{~s}$ per stack. One stack was acquired at the lumbar spine. Two 


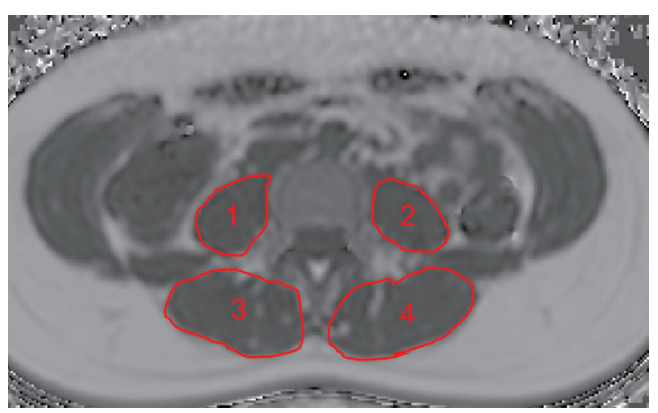

Figure 1 Representative segmentation of the right [1] and left [2] psoas muscle and the right [3] and left [4] erector spinae muscle.

stacks were needed to cover the entire thigh region. The six echoes were acquired in a single TR using non-flyback (bipolar) read-out gradients. A flip angle of $3^{\circ}$ was used to minimize T1 bias effects $(19,20)$.

\section{Muscle fat quantification, PDFF/CSA extraction and CMI calculation}

The gradient echo imaging data were processed online using the fat quantification routine of the MRI vendor (Philips Healthcare, Best, Netherlands). PDFF maps were generated using a complex-based water-fat separation algorithm that accounts for known confounding factors including a single $\mathrm{T} 2$ * correction, phase error correction and the consideration of the spectral complexity of fat using the multi-peak fat spectrum model of Ren et al. (21). Segmentations were performed by a radiologist using the free open-source software Medical Imaging Interaction Toolkit (MITK, developed by the Division of Medical and Biological Informatics, German Cancer Research Center, Heidelberg, Germany; www.mitk.org).

The psoas muscles and the erector spinae muscles were manually segmented bilaterally in the PDFF maps from the upper endplate of L2 to the lower endplate of L5 (Figure 1). On average 23 slices of the psoas muscle and the erector spinae were segmented in the axial plane. This approach was previously reported by Schlaeger et al. (20).

At the thigh, we firstly identified the cranial surface of the greater trochanter and caudal surface of femur condyles in each thigh. These were used as anatomical landmarks to define the most central slice of each thigh in the axial images. Then, both sides of the quadriceps femoris and the hamstring muscle groups were segmented manually in the 10 most central slices depicting the outer muscle contour of each muscle group (Figure 2). Segmentation time per subject amounted $15 \mathrm{~min}$. CSA $\left(\mathrm{mm}^{3}\right)$ and PDFF (in \%) were extracted and averaged over the right and left side. On basis of the extracted PDFF and CSA values the contractile mass index $(\mathrm{CMI})$ was calculated as follows: $\mathrm{CMI}=\mathrm{CSA} \times$ (1 - PDFF) (9).

\section{Statistical analysis}

For the statistical analyses SPSS (version 20.0; IBM SPSS Statistics for Windows, Armonk, NY, USA) was used. Statistical significance was considered at $\mathrm{P}<0.05$ (two-sided) in all conducted tests.

The Kolmogorov-Smirnov test indicated not normally distributed data. Differences in age, BMI, CSA, CMI, and PDFF of all muscles between male and female subjects were assessed with the Wilcoxon-Mann-Whitney-test. Correlations between PDFF and CMI of the different muscle groups were determined by using the Spearman correlation coefficient $r$.

\section{Results}

\section{Study population}

In the present study age was not significantly different between men and women (men: age: $30.5 \pm 4.9$ years; women: $29.9 \pm 7.0$ years; $\mathrm{P}=0.546$ ), neither was $\mathrm{BMI}$ (men: $27.6 \pm 2.8 \mathrm{~kg} / \mathrm{m}^{2}$; women: $25.8 \pm 1.4 \mathrm{~kg} / \mathrm{m}^{2} ; \mathrm{P}=0.085$ ) (Table 1 ).

\section{PDFF measurements}

No significant differences between men and women were detected in PDFF values of the psoas muscle $(\mathrm{P}=0.494)$, quadriceps femoris $(\mathrm{P}=0.520)$ and hamstring muscles $(\mathrm{P}=0.254)$. The erector spinae showed significantly different gender specific values $(\mathrm{P}=0.015)$ (Table 1). Representative color-coded PDFF maps of the corresponding muscle compartments in men and women are shown in Figures 3,4.

\section{CSA and CMI}

All CSA and CMI values calculated for the erector spinae, psoas, quadriceps and hamstring muscle groups showed significant differences between men and women $(\mathrm{P}<0.05$; Table 1).

\section{Correlations between muscle compartments}

The PDFF values for the erector spinae showed significant correlations with quadriceps muscle $(\mathrm{r}=0.400, \mathrm{P}=0.029)$ and 


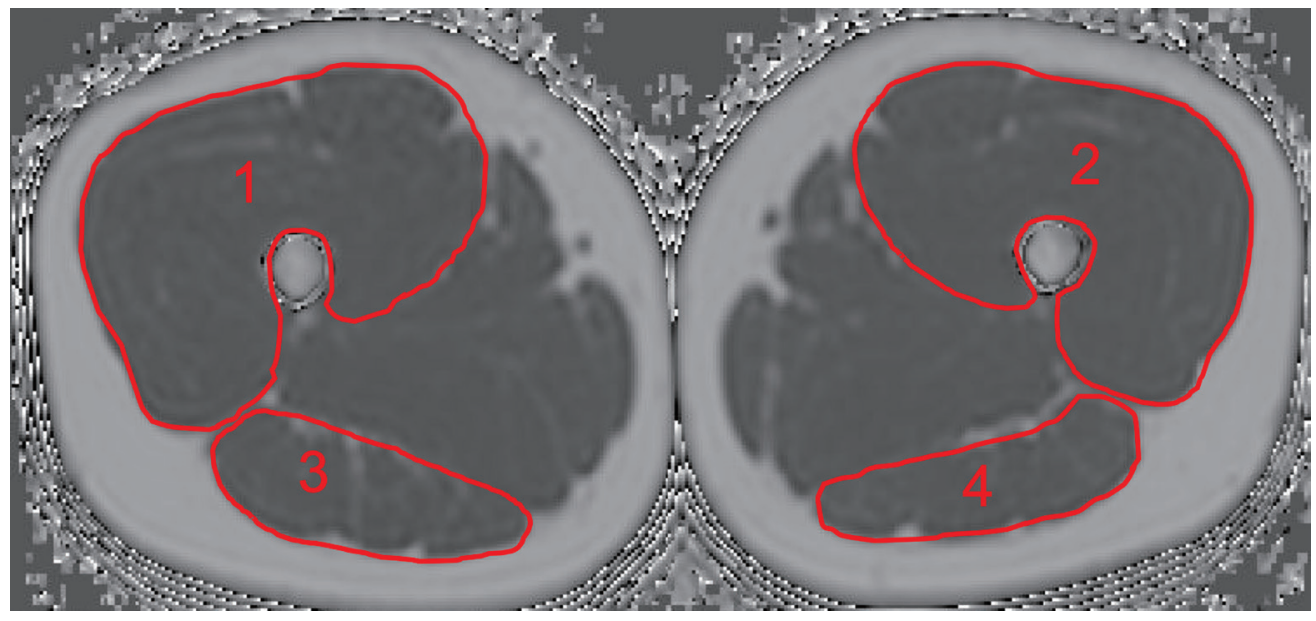

Figure 2 Representative segmentation of the thigh muscles: right [1] and left [2] quadriceps femoris muscle and the right [3] and left [4] hamstring musculature.

Table 1 Age, BMI, PDFF, CSA and CMI values of muscular compartments are shown. Parameters were compared between the two groups with Wilcoxon-Mann-Whitney-tests (P values)

\begin{tabular}{|c|c|c|c|}
\hline Characteristics & Mean & SD & $P$ \\
\hline Age (years) & & & 0.546 \\
\hline Men & 30.5 & 4.9 & \\
\hline Women & 29.9 & 7.1 & \\
\hline BMI $\left(\mathrm{kg} / \mathrm{m}^{2}\right)$ & & & 0.085 \\
\hline Men & 27.6 & 2.8 & \\
\hline Women & 25.8 & 1.4 & \\
\hline PDFF $_{\text {erector spinae }}(\%)$ & & & 0.015 \\
\hline Men & 9.5 & 2.4 & \\
\hline Women & 11.7 & 2.8 & \\
\hline PDFF $_{\text {psoas muscle }}(\%)$ & & & 0.494 \\
\hline Men & 6.2 & 7.1 & \\
\hline Women & 5.0 & 1.8 & \\
\hline $\operatorname{PDFF}_{\text {quadriceps femoris }}(\%)$ & & & 0.520 \\
\hline Men & 2.9 & 1.3 & \\
\hline Women & 2.6 & 1.3 & \\
\hline $\mathrm{PDFF}_{\text {hamstring group }}(\%)$ & & & 0.254 \\
\hline Men & 3.7 & 1.5 & \\
\hline Women & 4.4 & 2.2 & \\
\hline $\mathrm{CSA}_{\text {errector spinae }}\left(\mathrm{mm}^{2}\right)$ & & & $<0.0001$ \\
\hline Men & $3,396.9$ & 733.3 & \\
\hline Women & $2,276.3$ & 560.1 & \\
\hline
\end{tabular}

Table 1 (continued)
Table 1 (continued)

\begin{tabular}{|c|c|c|c|}
\hline Characteristics & Mean & SD & $\mathrm{P}$ \\
\hline $\mathrm{CSA}_{\text {psoas muscle }}\left(\mathrm{mm}^{2}\right)$ & & & $<0.0001$ \\
\hline Men & $1,798.3$ & 431.0 & \\
\hline Women & 771.3 & 247.9 & \\
\hline $\mathrm{CSA}_{\text {quadriceps femoris }}\left(\mathrm{mm}^{2}\right)$ & & & $<0.0001$ \\
\hline Men & $7,935.9$ & $1,651.5$ & \\
\hline Women & $5,424.1$ & 840.4 & \\
\hline $\mathrm{CSA}_{\text {hamstring group }}\left(\mathrm{mm}^{2}\right)$ & & & 0.002 \\
\hline Men & $2,285.9$ & 550.5 & \\
\hline Women & $1,589.7$ & 357.3 & \\
\hline $\mathrm{CMI}_{\text {erector spinae }}\left(\mathrm{mm}^{2}\right)$ & & & $<0.0001$ \\
\hline Men & $3,069.8$ & 650.1 & \\
\hline Women & $1,999.0$ & 475.6 & \\
\hline $\mathrm{CMI}_{\text {psoas muscle }}\left(\mathrm{mm}^{2}\right)$ & & & $<0.0001$ \\
\hline Men & $1,676.5$ & 385.3 & \\
\hline Women & 731.8 & 231.7 & \\
\hline $\mathrm{CMI}_{\text {quadricpes femoris }}\left(\mathrm{mm}^{2}\right)$ & & & $<0.0001$ \\
\hline Men & $7,688.6$ & 1.534 & \\
\hline Women & $5,283.1$ & 832.0 & \\
\hline $\mathrm{CMI}_{\text {hamstring group }}\left(\mathrm{mm}^{2}\right)$ & & & 0.001 \\
\hline Men & $2,199.2$ & 522.8 & \\
\hline Women & $1,520.3$ & 348.0 & \\
\hline
\end{tabular}

PDFF, proton density fat fraction; CSA, cross-sectional area; CMI, contractile mass index. 

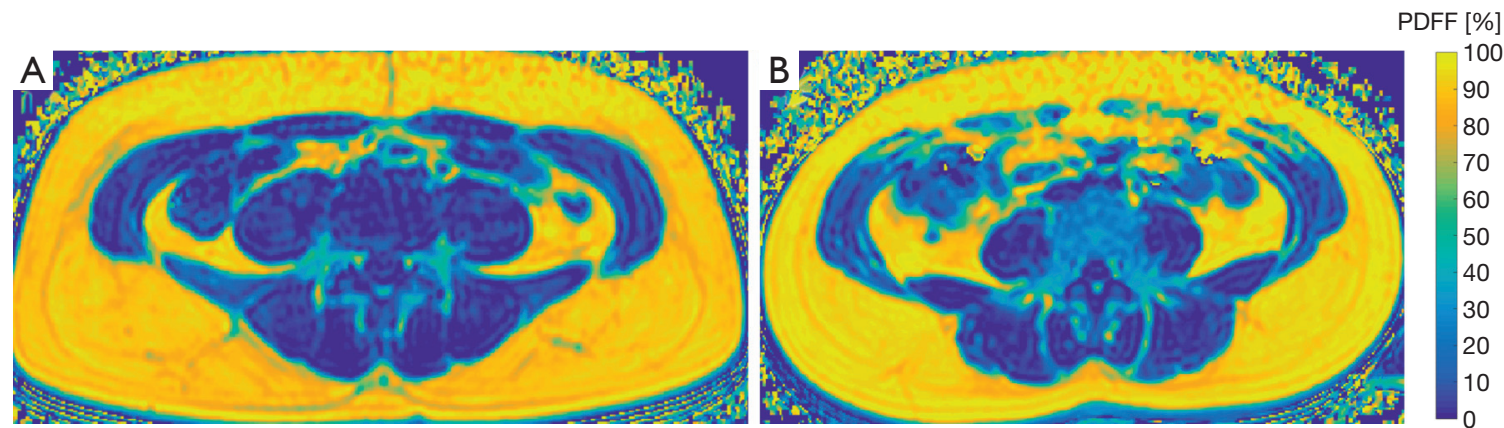

Figure 3 Color-coded maps. (A) Representative color-coded proton density fat fraction (PDFF) map of a 26-year-old male subject (mean PDFF of psoas muscle: 7.3\%; erector spinae muscle: 5.7\%); (B) representative color-coded PDFF map of a 22-year-old female subject (mean PDFF of psoas muscle: $14.3 \%$; erector spinae muscle: $5.6 \%$ ).
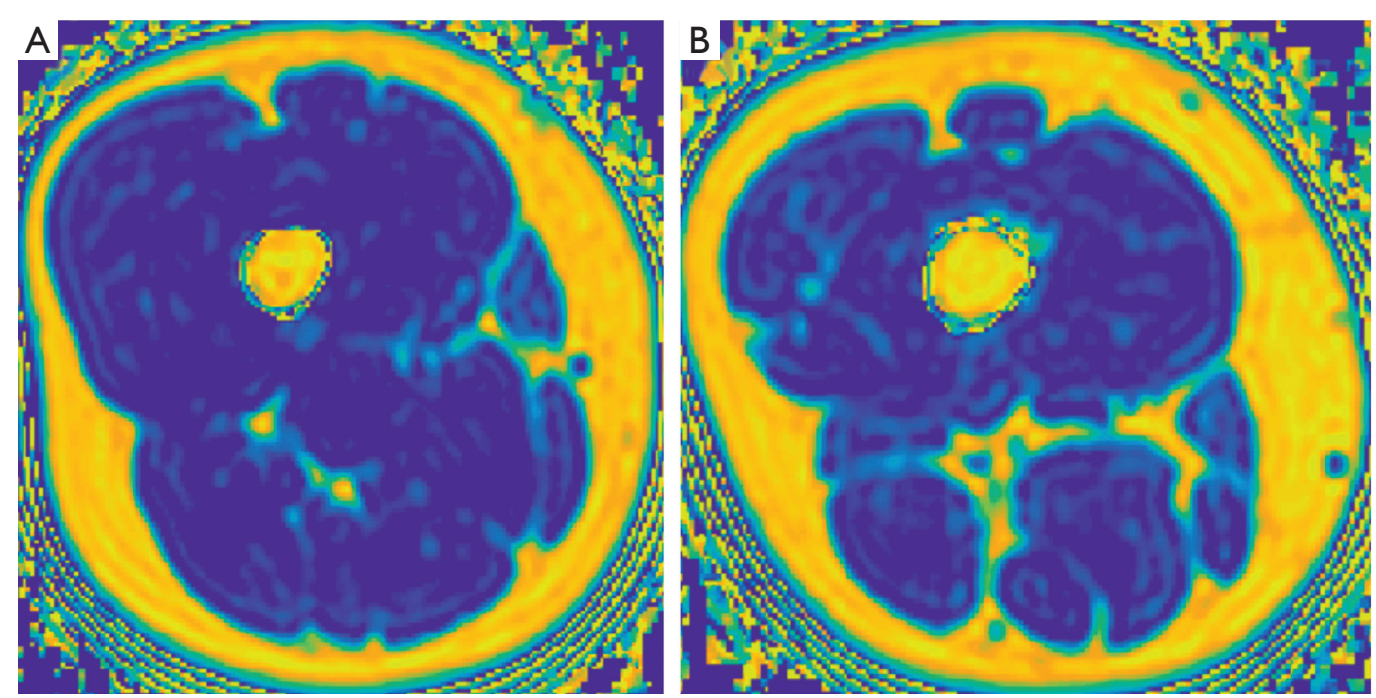

PDFF [\%]

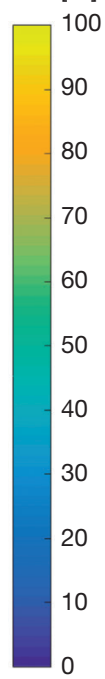

Figure 4 Color-coded maps. (A) Color-coded proton density fat fraction (PDFF) map of a 33-year-old female subject (PDFF of quadriceps femoris muscle: $1.0 \%$, hamstring muscle: $3.1 \%$ ); (B) color-coded PDFF map of a 22-year-old female (PDFF of quadriceps femoris muscle: $5.0 \%$; hamstring muscle: $7.2 \%)$.

the hamstring group $(\mathrm{r}=0.499, \mathrm{P}=0.005)$ (Figure 5). For the psoas muscle significant correlations could only be revealed for the hamstring group $(\mathrm{r}=0.390, \mathrm{P}=0.033)$ (Table 2). The CMI of the psoas muscle as well as the erector spinae showed significantly positive correlations with the quadriceps muscle $(\mathrm{r}=0.691, \mathrm{P}<0.0001$ and $\mathrm{r}=0.761$, $\mathrm{P}<0.0001)$ and the hamstring group $(\mathrm{r}=0.588, \mathrm{P}=0.001$ and $\mathrm{r}=0.603, \mathrm{P}<0.0001)($ Table 3 and Figure 6).

\section{Discussion}

In this study, the PDFF values of the erector spinae correlated weakly to moderately with those of the quadriceps and hamstring muscle groups, respectively. The PDFF of the psoas muscle only showed weak significant correlations with the quadriceps muscle. In contrast, the corresponding CMI values for the erector spinae and the psoas muscle showed strong significant correlations with the quadriceps and hamstring muscle groups. A potential reason for the much stronger correlations of the CMI compared to PDFF could be the inclusion of muscle CSA in parameter calculation. Furthermore, a rather concordant spatial fat distribution within the erector spinae, the thigh flexors and extensors could be shown.

Previous studies showed that characteristic structural and compositional peculiarities exist for different muscle 
A

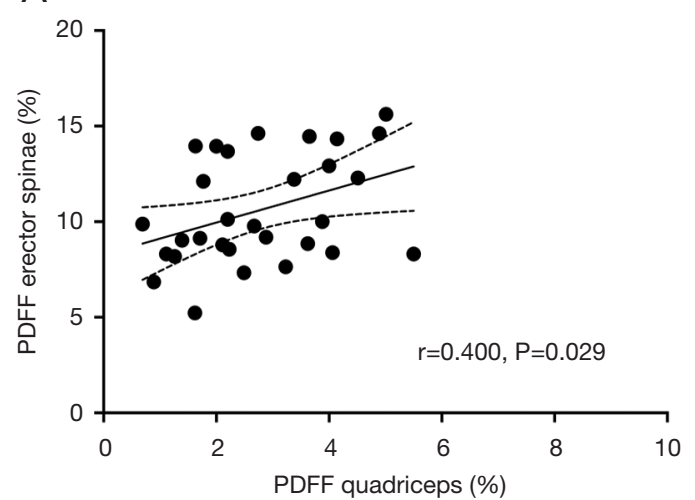

B

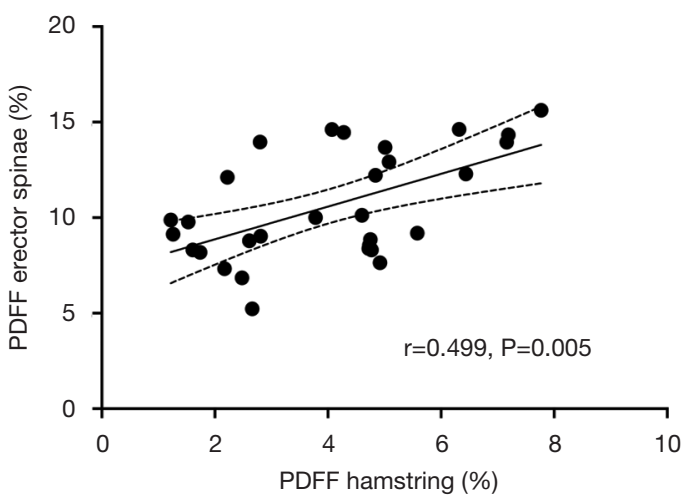

Figure 5 This figure plots the proton density fat fraction (PDFF) of the erector spinae against the quadriceps muscle (A) and the hamstring muscle group (B). The areas between the dotted lines represent the $95 \%$ confidence band of the best-fit line. PDFF, proton density fat fraction.

Table 2 Correlations ( $\mathrm{r}$ with corresponding $\mathrm{P}$ value) of the proton density fat fraction (PDFF) values of the erector spinae and psoas muscle with the quadriceps and hamstring muscles

\begin{tabular}{lcc}
\hline & PDFF $_{\text {erector spinae }}$ & PDFF $_{\text {psoas muscle }}$ \\
\hline PDFF $_{\text {quadriceps femoris }}$ & & \\
$r$ & 0.400 & 0.199 \\
$P$ & 0.029 & Not significant \\
PDFF $_{\text {hamstring group }}$ & & \\
$r$ & 0.499 & 0.390 \\
$P$ & 0.005 & 0.033 \\
\hline
\end{tabular}

Table 3 Correlations ( $\mathrm{r}$ with corresponding $\mathrm{P}$ value) of the contractile mass index $(\mathrm{CMI})$ values of the erector spinae and psoas muscle with the quadriceps and hamstring muscles

\begin{tabular}{lcc}
\hline & CMlerector spinae & CMl \\
\hline CMsoas muscle \\
\hline$r$ & 0.761 & 0.691 \\
$P$ & $<0.0001$ & $<0.0001$ \\
CMlhamstricpes femoris & \\
$r$ & & \\
$P$ & 0.603 & 0.588 \\
\hline
\end{tabular}

groups depending on their function and topography. These macroscopic and microscopic structural patterns are dependent on intra- and interindividual specifications like anatomic location, age and BMI (20,22-24). In contrast to the abundance of data on the physiology and pathology of musculoskeletal motion segments of the vertebral column there is a scarcity of information on thigh muscle composition (25-29). There are only few studies analyzing thigh muscle composition with state-of-the-art techniques like water-fat MRI. In the past several approaches towards muscle quality assessment using CT and T2 based MRI have been conducted allowing for extraction of CSA values and estimates for muscle fat fraction $(8,18)$.

A cross-sectional study by Kumar et al. revealed significant correlations between the degree of intramuscular fat accumulation in the quadriceps femoris verified by waterfat MRI and the presence and severity of knee osteoarthritis confirmed by conventional radiography and functional isokinetic strength measures (30). Furthermore, Grimm et al. showed that extracting PDFF values from MRS in semitendinosus muscle provides valid and reproducible surrogate parameters for muscle quality allowing for quantification of the tissue alterations and damage due to aging or muscular diseases (31).

Even if the correlations of the PDFF distribution patterns have to be considered rather weak, our findings point to resembling fatty infiltration mechanisms in the flexors and extensors of the thigh and the erector spinae muscle in this young cohort of subject with a representative BMI. A potential reason for the weak significance may be the relatively small sample size $(n=30)$. Keeping this drawback in mind it still can be concluded that the presented results indicate a rather homogenous muscle composition across paraspinal and thigh muscle groups except for the psoas muscle. The methodical reproducibility of the acquired sequence protocol was validated in previous studies on the thigh and paraspinal musculature $(20,32)$. 

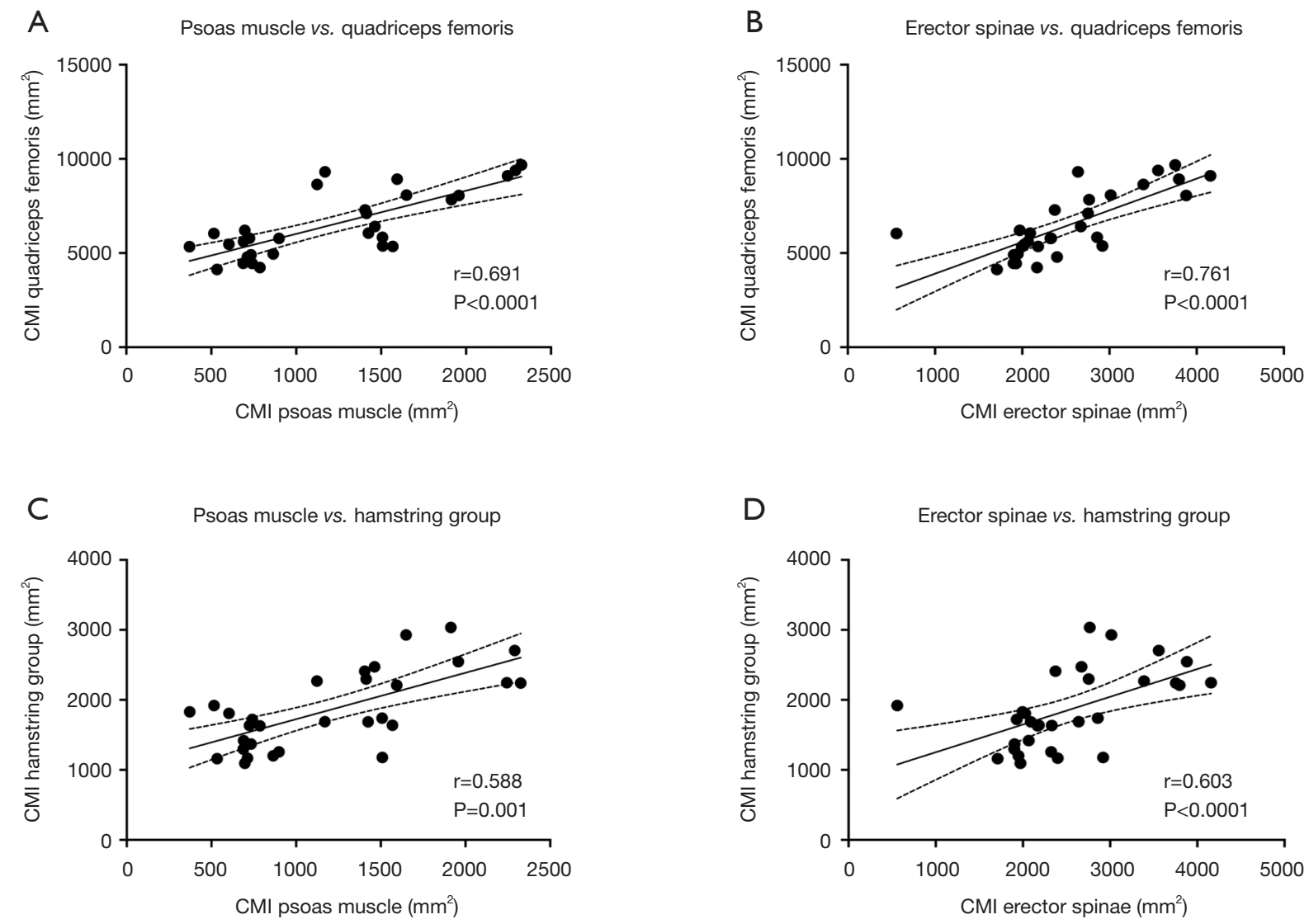

Figure 6 This figure plots the contractile mass index (CMI) of the psoas muscle against the quadriceps muscle (A) and the hamstring muscle group (B). Furthermore, the CMI of the erector spinae is plotted against the quadriceps muscle (C) and the hamstring femoris muscle group (D). The areas between the dotted lines represent the $95 \%$ confidence band of the best-fit line.

In the long-term future studies should focus on the exploration and establishment of valid and precise physiological ranges. Additionally, keeping the slight differences of approximately $1.5 \%$ changes in muscular fat fraction in mind detected by Kumar et al. discerning knee osteoarthritis from healthy controls, further studies investigating chemical shift encoding-based water fat MRI are needed, as in cases of subtle structural and compositional changes conventional T1-based qualitative imaging has its inherent methodical limits (30).

When interpreting the results of the present study there are certain limitations, which are elucidated in the following. First, the relatively small cohort size with a narrow age range limits this study with regard to aging. Additionally, the average BMI values of the subjects included in this study are considered overweight according to the World Health Organization (WHO). However, it has to be kept in mind that current estimates conducted by the
WHO state that, e.g., $65 \%$ of US adults are overweight to obese (33). Thus, the presented cohort can be considered representative regarding these global changes. In future studies, an analogously balanced but extended cohort with senescent subjects would be reasonable. Second, the crosssectional study design does not allow for evaluation of temporal and intraindividual dynamics.

\section{Conclusions}

In the present study, strong statistically significant correlations for CMI values of the erector spinae as well as the psoas muscle with the quadriceps and hamstring musculature could be revealed. Furthermore, the PDFF values for the erector spinae and both thigh muscle groups showed a comparable distribution range. The presented findings may indicate a certain association in regard of fatty infiltration patterns of these muscle groups. The concordant 
spatial fat accumulation within the analyzed muscles suggest the potential suitability as biomarkers in holistic muscle assessment approaches.

\section{Acknowledgments}

Funding: The present work received funding by the European Research Council (grant agreement No 677661 - ProFatMRI and grant agreement No 637164 - iBack), TUM Faculty of Medicine KKF grant H01, the German Research Foundation (DFG-SFB824/A9) and Philips Healthcare. Additionally, this work was supported by the German Research Foundation (DFG) and the Technical University of Munich (TUM) in the framework of the Open Access Publishing Program.

\section{Footnote}

Conflicts of Interest: The authors have no conflicts of interest to declare.

Ethical Statement: This study was approved by the Institutional Review Board and was conducted in accordance with the Declaration of Helsinki. Written informed consent was obtained from all study participants.

\section{References}

1. Cruz-Jentoft AJ, Bahat G, Bauer J, Boirie $\mathrm{Y}$, Bruyère $\mathrm{O}$, Cederholm T, Cooper C, Landi F, Rolland Y, Sayer AA, Schneider SM, Sieber CC, Topinkova E, Vandewoude M, Visser M, Zamboni M; Writing Group for the European Working Group on Sarcopenia in Older People 2 (EWGSOP2), and the Extended Group for EWGSOP2. Sarcopenia: revised European consensus on definition and diagnosis. Age Ageing 2019;48:16-31.

2. Marcus RL, Addison O, Dibble LE, Foreman KB, Morrell G, Lastayo P. Intramuscular adipose tissue, sarcopenia, and mobility function in older individuals. J Aging Res 2012;2012:629637.

3. Tuttle LJ, Sinacore DR, Mueller MJ. Intermuscular adipose tissue is muscle specific and associated with poor functional performance. J Aging Res 2012;2012:172957.

4. Fearon K, Strasser F, Anker SD, Bosaeus I, Bruera E, Fainsinger RL, Jatoi A, Loprinzi C, MacDonald N, Mantovani G, Davis M, Muscaritoli M, Ottery F, Radbruch L, Ravasco P, Walsh D, Wilcock A, Kaasa S, Baracos VE. Definition and classification of cancer cachexia: an international consensus. Lancet Oncol 2011;12:489-95.

5. Blum D, Stene GB, Solheim TS, Fayers P, Hjermstad MJ, Baracos VE, Fearon K, Strasser F, Kaasa S; EuroImpact. Validation of the Consensus-Definition for Cancer Cachexia and evaluation of a classification model--a study based on data from an international multicentre project (EPCRC-CSA). Ann Oncol 2014;25:1635-42.

6. Pausch T, Hartwig W, Hinz U, Swolana T, Bundy BD, Hackert T, Grenacher L, Büchler MW, Werner J. Cachexia but not obesity worsens the postoperative outcome after pancreatoduodenectomy in pancreatic cancer. Surgery 2012;152:S81-8.

7. Furtner J, Berghoff AS, Albtoush OM, Woitek R, Asenbaum U, Prayer D, Widhalm G, Gatterbauer B, Dieckmann K, Birner P, Aretin B8, Bartsch R, Zielinski CC, Schöpf V, Preusser M. Survival prediction using temporal muscle thickness measurements on cranial magnetic resonance images in patients with newly diagnosed brain metastases. Eur Radiol 2017;27:3167-73.

8. MacDonald AJ, Miller J, Ramage MI, Greig C, Stephens NA, Jacobi C, Preston T, Fearon KCH, Skipworth RJE. Cross sectional imaging of truncal and quadriceps muscles relates to different functional outcomes in cancer. Clin Nutr 2019;38:2875-80.

9. Carlier PG, Marty B, Scheidegger O, Loureiro de Sousa P, Baudin PY, Snezhko E, Vlodavets D. Skeletal Muscle Quantitative Nuclear Magnetic Resonance Imaging and Spectroscopy as an Outcome Measure for Clinical Trials. J Neuromuscul Dis 2016;3:1-28.

10. Baum T, Cordes C, Dieckmeyer M, Ruschke S, Franz D, Hauner H, Kirschke JS, Karampinos DC. MR-based assessment of body fat distribution and characteristics. Eur J Radiol 2016;85:1512-8.

11. Hu HH, Kan HE. Quantitative proton MR techniques for measuring fat. NMR Biomed 2013;26:1609-29.

12. Azzabou N, Hogrel JY, Carlier PG. NMR based biomarkers to study age-related changes in the human quadriceps. Exp Gerontol 2015;70:54-60.

13. Barnouin Y, Butler-Browne G, Voit T, Reversat D, Azzabou N, Leroux G, Behin A, McPhee JS, Carlier PG, Hogrel JY. Manual segmentation of individual muscles of the quadriceps femoris using MRI: a reappraisal. J Magn Reson Imaging 2014;40:239-47.

14. Fortin M, Videman T, Gibbons LE, Battie MC. Paraspinal muscle morphology and composition: a 15-yr longitudinal magnetic resonance imaging study. Med Sci Sports Exerc 2014;46:893-901.

15. Dahlqvist JR, Vissing CR, Hedermann G, Thomsen C, 
Vissing J. Fat replacement of paraspinal muscles with aging in healthy adults. Med Sci Sports Exerc 2017;49:595-601.

16. Crawford RJ, Filli L, Elliott JM, Nanz D, Fischer MA, Marcon M, Ulbrich EJ. Age- and level-dependence of fatty infiltration in lumbar paravertebral muscles of healthy volunteers. AJNR Am J Neuroradiol 2016;37:742-8.

17. Valentin S, Licka T, Elliott J. Age and side-related morphometric MRI evaluation of trunk muscles in people without back pain. Man Ther 2015;20:90-5.

18. Marcon M, Ciritsis B, Laux C, Nanz D, Fischer MA, Andreisek G, Ulbrich EJ. Quantitative and qualitative MRimaging assessment of vastus medialis muscle volume loss in asymptomatic patients after anterior cruciate ligament reconstruction. J Magn Reson Imaging 2015;42:515-25.

19. Karampinos DC, Yu H, Shimakawa A, Link TM, Majumdar S. T(1)-corrected fat quantification using chemical shift-based water/fat separation: application to skeletal muscle. Magn Reson Med 2011;66:1312-26.

20. Schlaeger S, Inhuber S, Rohrmeier A, Dieckmeyer M, Freitag F, Klupp E, Weidlich D, Feuerriegel G, Kreuzpointner F, Schwirtz A, Rummeny EJ, Zimmer C, Kirschke JS, Karampinos DC, Baum T. Association of paraspinal muscle water-fat MRI-based measurements with isometric strength measurements. Eur Radiol 2019;29:599-608.

21. Ren J, Dimitrov I, Sherry AD, Malloy CR. Composition of adipose tissue and marrow fat in humans by $1 \mathrm{H}$ NMR at 7 Tesla. J Lipid Res 2008;49:2055-62.

22. Burian E, Syväri J, Holzapfel C, Drabsch T, Kirschke JS, Rummeny EJ, Zimmer C, Hauner H, Karampinos DC, Baum T, Franz D. Gender- and Age-Related Changes in Trunk Muscle Composition Using Chemical Shift EncodingBased Water(-)Fat MRI. Nutrients 2018;10:E1972.

23. Ruschke S, Pokorney A, Baum T, Eggers H, Miller JH, $\mathrm{Hu} \mathrm{HH}$, Karampinos DC. Measurement of vertebral bone marrow proton density fat fraction in children using quantitative water-fat MRI. MAGMA 2017;30:449-60.

24. Sollmann N, Dieckmeyer M, Schlaeger S, Rohrmeier A, Syvaeri J, Diefenbach MN, Weidlich D, Ruschke S, Klupp E, Franz D, Rummeny EJ, Zimmer C, Kirschke JS, Karampinos DC, Baum T. Associations Between Lumbar Vertebral Bone Marrow and Paraspinal Muscle Fat Compositions-An Investigation by Chemical Shift Encoding-Based Water-Fat MRI. Front Endocrinol (Lausanne) 2018;9:563.

25. Ranger TA, Cicuttini FM, Jensen TS, Peiris WL, Hussain SM, Fairley J, Urquhart DM. Are the size and composition of the paraspinal muscles associated with low back pain? A systematic review. Spine J 2017;17:1729-48.
26. Teichtahl AJ, Urquhart DM, Wang Y, Wluka AE, Wijethilake P, O'Sullivan R, Cicuttini FM. Fat infiltration of paraspinal muscles is associated with low back pain, disability, and structural abnormalities in communitybased adults. Spine J 2015;15:1593-601.

27. Malakoutian M, Street J, Wilke HJ, Stavness I, Dvorak M, Fels S, Oxland T. Role of muscle damage on loading at the level adjacent to a lumbar spine fusion: a biomechanical analysis. Eur Spine J 2016;25:2929-37.

28. Danneels L, Cagnie B, D'hooge R, De Deene Y, Crombez G, Vanderstraeten G, Parlevliet T, Van Oosterwijck J. The effect of experimental low back pain on lumbar muscle activity in people with a history of clinical low back pain: a muscle functional MRI study. J Neurophysiol 2016;115:851-7.

29. Hildebrandt M, Fankhauser G, Meichtry A, Luomajoki H. Correlation between lumbar dysfunction and fat infiltration in lumbar multifidus muscles in patients with low back pain. BMC Musculoskelet Disord 2017;18:12.

30. Kumar D, Karampinos DC, MacLeod TD, Lin W, Nardo L, Li X, Link TM, Majumdar S, Souza RB. Quadriceps intramuscular fat fraction rather than muscle size is associated with knee osteoarthritis. Osteoarthritis Cartilage 2014;22:226-34.

31. Grimm A, Meyer H, Nickel MD, Nittka M, Raithel E, Chaudry O, Friedberger A, Uder M, Kemmler W, Engelke K, Quick HH. Repeatability of Dixon magnetic resonance imaging and magnetic resonance spectroscopy for quantitative muscle fat assessments in the thigh. J Cachexia Sarcopenia Muscle 2018;9:1093-100.

32. Baum T, Inhuber S, Dieckmeyer M, Cordes C, Ruschke S, Klupp E, Jungmann PM, Farlock R, Eggers H, Kooijman H, Rummeny EJ, Schwirtz A, Kirschke JS, Karampinos DC. Association of Quadriceps Muscle Fat With Isometric Strength Measurements in Healthy Males Using Chemical Shift Encoding-Based Water-Fat Magnetic Resonance Imaging. J Comput Assist Tomogr 2016;40:447-51.

33. World Health Organization. WHO Media Centre. Obesity and overweight: fact sheet (No. 311). 2015.

Cite this article as: Burian E, Inhuber S, Schlaeger S, Dieckmeyer M, Klupp E, Franz D, Weidlich D, Sollmann N, Löffler M, Schwirtz A, Rummeny EJ, Zimmer C, Kirschke JS, Karampinos DC, Baum T. Association of thigh and paraspinal muscle composition in young adults using chemical shift encoding-based water-fat MRI. Quant Imaging Med Surg 2020;10(1):128-136. doi: 10.21037/qims.2019.11.08 